\title{
Resveratrol Protects Against Methotrexate-Induced Hepatic Injury in Rats
}

\author{
Tugba Tunali-Akbay ${ }^{1 *}$, Ozer Sehirli², Feriha Ercan ${ }^{3}$, Goksel Sener $^{2}$ \\ ${ }^{1}$ Marmara University School of Dentistry, Department of Biochemistry, Istanbul / Turkey \\ ${ }^{2}$ Marmara University School of Pharmacy, Department of Pharmacology, Istanbul / Turkey \\ ${ }^{3}$ Marmara University School of Medicine, Department of Histology \& Embryology, Istanbul/Turkey
}

Received, March 16, 2010; Revised, June 28, 2010; Accepted, August 27, 2010; Published, August 27, 2010

\begin{abstract}
Purpose. The aim of this study was to investigate the possible protective effect of resveratrol on some liver and blood parameters in methotrexate (MTX) induced toxicity in rats. MTX is used widely to treat various neoplastic diseases such as acute lymphoblastic leukemia, lymphoma, solid cancers, and autoimmune diseases. We hypothesized that resveratrol has a potential to decrease the oxidant damage in MTX-induced hepatic injury. Methods. Following a single dose of methotrexate $(20 \mathrm{mg} / \mathrm{kg}$, i.p.), either saline or resveratrol $(10 \mathrm{mg} / \mathrm{kg}$, orally) was administered for 5 days. After decapitation of the rats, trunk blood was obtained and the liver was removed to measure malondialdehyde (MDA) and glutathione (GSH) levels, myeloperoxidase (MPO) and tissue factor (TF) activities and collagen content. Aspartate aminotransferase (AST), alanine aminotransferase (ALT) and lactate dehydrogenase (LDH) activity were measured in the serum samples, while TNF- $\alpha$ and total antioxidant capacity were assayed in plasma samples. Results. Our results showed that MTX administration increased the hepatic MDA levels, MPO and TF activities and collagen contents and decreased GSH, while these alterations were reversed in resveratroltreated group. Elevated AST and ALT activities ALT and TNF- $\alpha$ level observed following MTX treatment was depressed with resveratrol. . Conclusions. The present study showed that resveratrol protects against MTX-induced hepatic injury and may be of therapeutic potential in alleviating the systemic side effects of this chemotherapeutic agent.
\end{abstract}

\section{INTRODUCTION}

Methotrexate (MTX) is one of the immunosuppressory compounds applied in the prophylaxis and treatment of several diseases, including: rheumatoid arthritis, systemic lupus erythematosus, psoriasis, graft-versus-host disease and, in combination with other drugs, neoplastic diseases $(1,2)$.

MTX antagonizes folate metabolism and inhibits the de novo synthesis of thymidine and purine, constituent factors of nucleic acid, resulting in the inhibition of proliferation of rapidly dividing cells such as cancer cells $(2,3)$. The efficacy of this compound, a widely used cytotoxic chemotherapeutic agent, is often limited by its severe hepatotoxicity $(4,5,6)$.

Resveratrol $\left(3,4^{\prime}, 5\right.$-trihydroxystilbene) is a phytoalexin found in a wide variety of dietary sources including grapes, plums and peanuts. It is also present in wines, especially red wines and to a much lesser extent in white wines. During the last years, it has been the focus of numerous in vitro and in vivo studies, which investigate its biological attributes, mainly antioxidant and antiinflammatory activities, anti-platelet effect, anti- atherogenic property, estrogen-like growthpromoting effect, growth-inhibiting activity, immunomodulation and chemoprevention $(7,8)$. Resveratrol is both a free radical scavenger and a potent antioxidant because of its ability to promote the activities of a variety of antioxidant enzymes $(9,10)$. The ability of the polyphenolic compounds to act as antioxidants depends on the redox properties of their phenolic hydroxyl groups and the potential for electron delocalization across the chemical structure (11, 12).

The common recognition of resveratrol as a natural antioxidant was clarified by Zini et al. (13). It has three different antioxidant mechanisms: (i) competition with coenzyme Q and, to decrease the oxidative chain complex, the site of reactive oxygen species generation, (ii) scavenging $\mathrm{O}_{2}{ }^{--}$radicals formed in the mitochondria and (iii) inhibition of lipid peroxidation induced by Fenton reaction products.

Corresponding Author: Tugba Tunali Akbay, Marmara University , Faculty of Dentistry, Department of Basic Sciences, Nisantasi, 34365, Istanbul, Turkey. E-mail: ttunali@marmara.edu.tr 
In fact, numerous studies have demonstrated the ability of resveratrol to scavenge both $\mathrm{O}_{2}{ }^{-}$and OH radicals $(14,15)$. By contrast, in a study by Orallo et al. (16), using the enzymatic hypoxanthine oxidase- $\mathrm{XO}$ (xanthine oxidase) system, resveratrol neither affected the XO activity nor scavenged $\mathrm{O}_{2}{ }^{-}$radicals in rat macrophage extracts.

In view of the above findings, we hypothesized that resveratrol, potent free radical scavenger, has the potential to protect liver tissue against experimental MTX toxicity. This study illustrate for the first time that MTX-induced elevation in myeloperoxidase (MPO) activity , which plays a fundamental role in oxidant production by neutrophils, was inhibited by resveratrol treatment, indicating the antioxidative effect of resveratrol may be neutrophil-dependent. However, another original parameter that is measured in this MTX toxicity and in resveratrol treatment was tissue factor (TF) activity of the liver, which shows the bleeding tendency and/or the healing state of the damaged tissue. The present study also shows the elevation of decreased TF activity in liver was reversed by resveratrol treatment in MTX toxicity.

\section{METHODS}

\section{Experimental design}

All experimental protocols were approved by the Marmara University School of Medicine Animal Care and Use Committee. Both sexes of Wistar albino rats (200-250 g, 3 months old) were kept at a constant temperature $\left(22 \pm 1^{\circ} \mathrm{C}\right)$ with $12 \mathrm{~h}$ light and dark cycles. Following a single dose of methotrexate $(20 \mathrm{mg} / \mathrm{kg}$, i.p.), either saline or resveratrol $(10 \mathrm{mg} / \mathrm{kg}$, orally) was administered for 5 days. Each group consisted of eight rats. Equal number of male and female rats were used in each group as there were no statistical difference between their results.

After decapitation of the rats, trunk blood was obtained and the liver was removed to measure malondialdehyde (MDA) (17) and glutathione (GSH) (18) levels, MPO (19) and TF activities (20) and collagen content (21). Aspartate aminotransferase (AST), alanine aminotransferase (ALT), and lactate dehydrogenase (LDH) activities were measured in the serum samples, while TNF- $\alpha$ in serum (Biosource Europe S.A., Nivelles, Belgium) was evaluated by an RIAIRMA (radioimmunoassay-immunoradiometric assay) method. Total antioxidant capacity (AOC), in plasma samples, was measured by using colorimetric test system (ImAnOx, Catalog Number: KC5200, Immunodiagnostic AG, D64625, Bensheim) according to the instructions provided by manufacturer.

\section{MDA and GSH assays}

Liver tissue samples were homogenized in ice cold $150 \mathrm{mM} \mathrm{KCl}$ for determination of MDA and GSH levels. The MDA levels were assayed for products of lipid peroxidation (17). Results are expressed as nmol MDA/g tissue. GSH was determined by the spectrophotometric method using the Ellman's reagent (18). Results are expressed $\mu \mathrm{mol}$ GSH/g tissue. Serum MDA and GSH levels were measured by the same methods.

\section{MPO activity}

Tissue associated MPO activity was measured using a procedure similar to that documented by Hillegas et al. (19). Liver samples were homogenized in $50 \mathrm{mM}$ potassium phosphate buffer (PB, pH 6.0), and centrifuged at 41,400 g (10 min); pellets were suspended in $50 \mathrm{mM} \mathrm{PB}$ containing $0.5 \%$ hexadecyltrimethylammonium bromide. After three freeze and thaw cycles, with sonication between cycles, the samples were centrifuged at $41,400 \mathrm{~g}$ for $10 \mathrm{~min}$. Aliquots $(0.3 \mathrm{~mL})$ were added to $2.3 \mathrm{~mL}$ of reaction mixture containing $50 \mathrm{mM} \mathrm{PB}$, odianisidine, and $20 \mathrm{mM} \mathrm{H}_{2} \mathrm{O}_{2}$ solution. One unit (U) of enzyme activity was defined as the amount of the MPO present per gram of tissue weight that caused a change in absorbance of $1.0 \mathrm{~min}^{-1}$ at $460 \mathrm{~nm}$ and $37^{\circ} \mathrm{C}$. MPO activity is expressed as $\mathrm{U} / \mathrm{g}$ tissue.

\section{TF activity}

TF activity of liver tissues was evaluated according to Quick's one stage method using normal plasma (20). This was performed by mixing $0.1 \mathrm{~mL}$ liver homogenate with $0.1 \mathrm{~mL}$ of plasma, with the clotting reaction being started on addition of $0.02 \mathrm{M} \mathrm{CaCl} 2$. All reagents were in the reaction temperature (37 $\left.{ }^{0} \mathrm{C}\right)$ before admixture. TF activity was expressed as seconds.

\section{Tissue collagen measurement}

Tissue collagen was measured as a free radical induced fibrosis marker. Tissue samples were cut with a razor blade and immediately fixed in $10 \%$ formalin in $0.1 \mathrm{~mol} / \mathrm{L}$ phosphate buffer $(\mathrm{pH}$ 7.2) and embedded in paraffin, and approximately $15 \mu \mathrm{m}$ thick sections were obtained. Evaluation of collagen content was based on the 
selective binding of Sirius red and Fast green FCF to collagen and noncollagenous components, respectively, when the sections were stained with both dyes dissolved in aqueous saturated picric acid. Both dyes were eluted readily and simultaneously by using $0.1 \mathrm{~mol} / \mathrm{L}$ $\mathrm{NaOH}-$ methanol $(1: 1 \mathrm{v} / \mathrm{v})$. Finally, the absorbances at 540 and $605 \mathrm{~nm}$ were used to determine the amounts of collagen and protein, respectively (21).

\section{Microscopic Evaluation}

For the light microscopic investigations, tissue specimens from the liver were fixed with $10 \%$ formaldehyde and processed routinely for embedding in paraffin. Tissue sections of $5 \mu \mathrm{m}$ were stained with hematoxylin and eosin (H\&E) and examined under an Olympus BHX51 (Tokyo, Japan) photomicroscope.

\section{STATISTICS}

Statistical analysis was carried out using Graph Pad Prism 3.0 (Graph Pad Software, San Diego, CA, USA). Groups of data were compared with an analysis of variance (ANOVA) followed by Tukey's multiple comparison tests. Values of $\mathrm{p}<0.05$ were regarded as significant.

\section{RESULTS}

As shown in Table 1 serum AST, ALT and LDH levels were significantly higher in the salinetreated MTX group when compared with those of the control group $(p<0.001)$ while resveratrol treatment reversed these parameters significantly.

Elevated TNF- $\alpha$ levels $(26.5 \pm 3.2 \mathrm{pg} / \mathrm{ml}$, $\mathrm{p}<0.001)$ and decreased AOC $(215 \pm 29.6 \mathrm{pg} / \mathrm{ml})$ observed following MTX treatment were reversed with resveratrol treatment $(9.96 \pm 1.4 \mathrm{pg} / \mathrm{ml}$ and $429 \pm 26.8 \mathrm{pg} / \mathrm{ml}$, respectively, $\mathrm{p}<0.01$; Figure 1).

Methotrexate treatment decreased the liver GSH levels significantly $(0.92 \pm 0.1 \mu \mathrm{mol} / \mathrm{g}, \mathrm{p}<$ $0.01)$ almost to $55 \%$ of the control $(2.35 \pm 0.2$ $\mu \mathrm{mol} / \mathrm{g}$ ), while resveratrol treatment following MTX prevented this reduction in GSH $(1.93 \pm 0.2$ $\mu \mathrm{mol} / \mathrm{g} \mathrm{p}<0.05$ ) (Fig. 2a).
The levels of liver MDA, as products of lipid peroxidation, were increased after treatment with MTX to levels $(83.2 \pm 5.4 \mathrm{nmol} / \mathrm{g})$ that are found to be significantly higher than the control group animals $(43.8 \pm 5.3 \mathrm{nmol} / \mathrm{g}, \mathrm{p}<0.001)$. On the other hand, resveratrol treatment following the MTX challenge reversed MDA levels back almost to the control values $(50.1 \pm 4.3 \mathrm{nmol} / \mathrm{g}, \mathrm{p}<0.01)$ (Figure 2b).

Tissue MPO activity was measured as an indirect evidence of neutrophil infiltration. MTX treatment caused significant increase in the liver MPO activity $(41.1 \pm 4.4 \mathrm{U} / \mathrm{g}, \mathrm{p}<0.001)$ which was significantly higher than that of the control group $(11.8 \pm 1.9 \mathrm{U} / \mathrm{g})$, while resveratrol treatment reversed this level $(22.0 \pm 3.1 \mathrm{U} / \mathrm{g}$, $\mathrm{p}<0.05$ ) (Figure 2c).

Collagen contents of the liver tissue were increased following MTX treatment $(50.3 \pm 3.9$ $\mu \mathrm{g} / \mathrm{mg}$ protein, $\mathrm{p}<0.001)$ as a measure of enhanced fibrotic activity (Figure 2d). On the other hand, increased collagen levels were reversed to control levels by resveratrol treatment (control: 26. $3 \pm 3.4 \mu \mathrm{g} / \mathrm{mg}$ protein, and resveratrol treated MTX group: $26.8 \pm 3.5 \mu \mathrm{g} / \mathrm{mg}$ protein).

As TF activity has been measured by PT test, shortened clot formation time shows increased TF activity. TF activity of MTX group (108. $9 \pm 6.8$ s) was significantly increased when compared to the control group $(67.7 \pm 6.9 \mathrm{~s}, \mathrm{p}<0.001)$ (Figure $3)$. Resveratrol treatment significantly decreased TF activity of MTX group (74.9 $\pm 5.5 \mathrm{~s}$, $\mathrm{p}<0.001$ ).

In MTX-treated group, liver parenchyma showed degenerated hepatocytes, dilatation, and vascular congestion in sinusoids, increased number of activated Kupffer cells and inflammatory cell infiltration around portal area and central vein; In resveratrol-treated MTX group, regular hepatocytes and mild activated Kupffer cells, were present in most region of the liver parenchyma (Figure 4).

\begin{tabular}{|c|c|c|c|c|}
\hline & \multicolumn{2}{|c|}{ Control } & \multicolumn{2}{|c|}{ MTX } \\
\hline & Saline-treated & RVT-treated & Saline-treated & RVT-treated \\
\hline AST (U/L) & $258.2 \pm 16.9$ & $266.0 \pm 17.6$ & $611.0 \pm 64.7 * * *$ & $320.8 \pm 29.0^{+++}$ \\
\hline ALT (U/L) & $82.8 \pm 12.2$ & $88.5 \pm 13.0$ & $259.0 \pm 24.7 * * *$ & $122.8 \pm 16.8^{+++}$ \\
\hline LDH (U/L) & $1802 \pm 134$ & $1848 \pm 122$ & $4975 \pm 294 * * *$ & $2734 \pm 323^{+++}$ \\
\hline
\end{tabular}




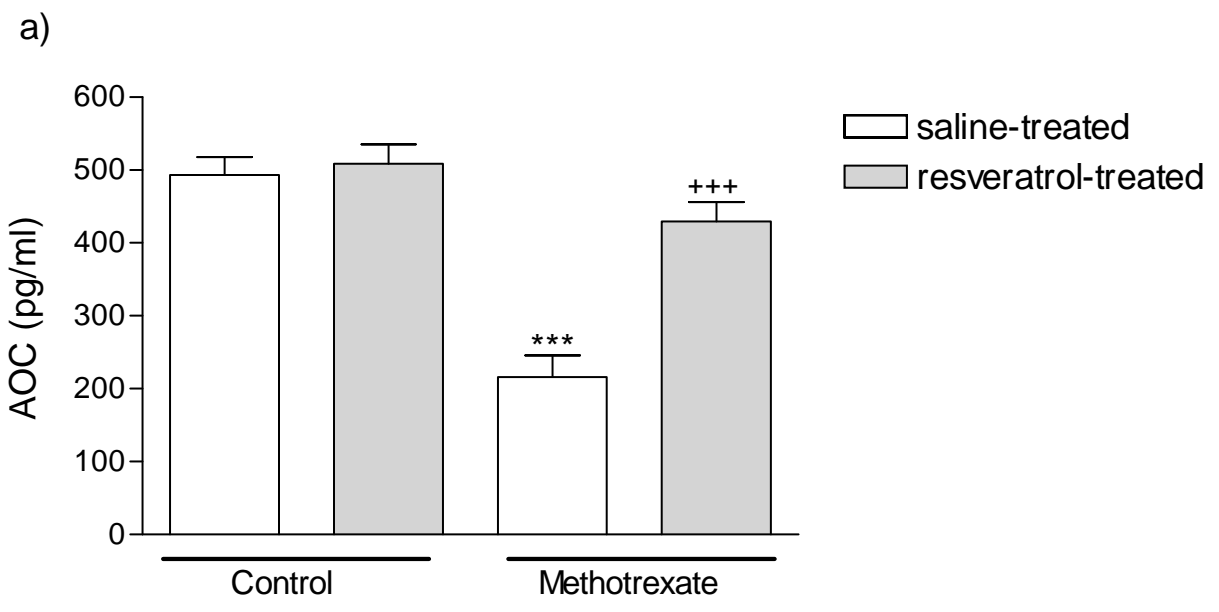

b)

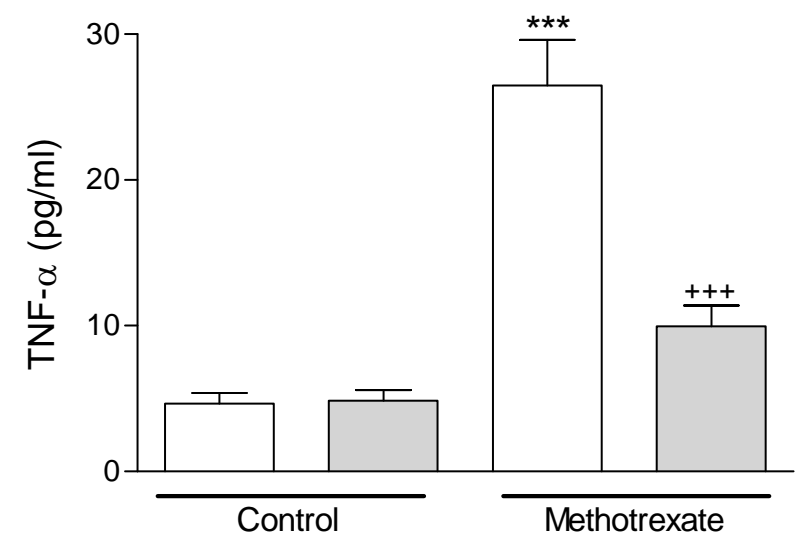

Figure 1: a) Plasma antioxidant capacity (AOC) and b) tumor necrosis factor alfa (TNF- $\alpha$ ) levels in the saline- or resveratrol treated control and methotrexate methotrexategroups. Each group consists of eight animals. ${ }^{* * *}: \mathrm{p}<0.01$ compared with control group, $+++: \mathrm{p}<0.01$ compared with methotrexate group.

\section{DISCUSSION}

Over the past five decades, low-dose MTX has been used for the treatment of various inflammatory diseases such as psoriatic and rheumatoid arthritis. MTX-induced toxicity appears to be a consequence of the interaction of many factors: dosing schedule and length of treatment, patients' risk factors, type of disease, and presence of genetic and molecular apoptotic factors $(22,23)$. The results of the present study demonstrate that MTX treatment causes oxidative tissue damage, as assessed by increased lipid peroxidation, myeloperoxidase activity and collagen contents. Moreover, GSH levels were decreased in the liver. Lipid peroxidation, mediated by oxygen free radicals, is believed to be an important cause of destruction and damage to cell membranes and has been suggested to be a contributing factor to the development of MTX mediated tissue damage (24).

The conversion of MTX to its major extracellular metabolite, 7-hydoxymethotrexate, takes place in the liver, where it is oxidized by a soluble enzymatic system (25). Inside cells, MTX is stored in a polyglutamated form (26). Longterm drug administration can cause accumulation of MTX polyglutamates and decreased folate levels $(27,28)$. The presence of higher levels of polyglutamates causes a longer intracellular presence of the drug, and this has been suggested as a mechanism for MTX hepatotoxicity $(27,29)$. 
a)

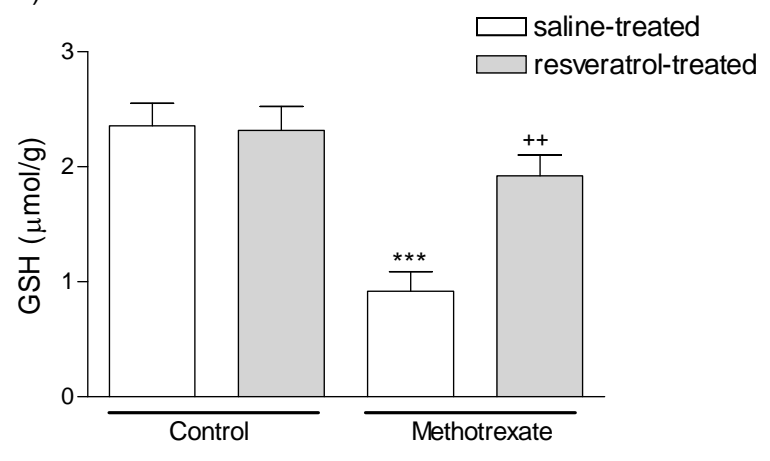

c)

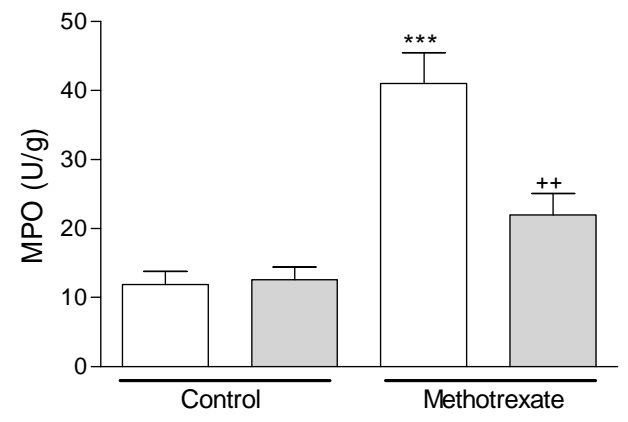

b)

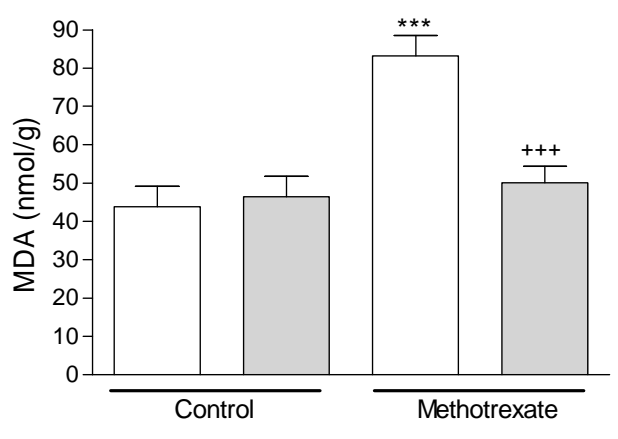

d)

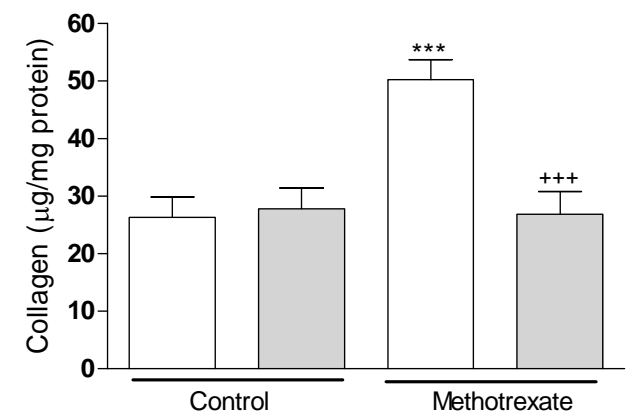

Figure 2: a) Glutathione (GSH), and b) malondialdehyde (MDA) levels, c) myeloperoxidase (MPO) activity and d) collagen contents in the liver tissues of saline- or resveratrol treated control and MTX groups. Each group consists of eight animals. ${ }^{* * *} \mathrm{p}<0.01$ compared with control group, $++\mathrm{p}<0.05$ compared with methotrexate (MTX) group, +++ $\mathrm{p}<0.01$ compared with methotrexate (MTX) group.

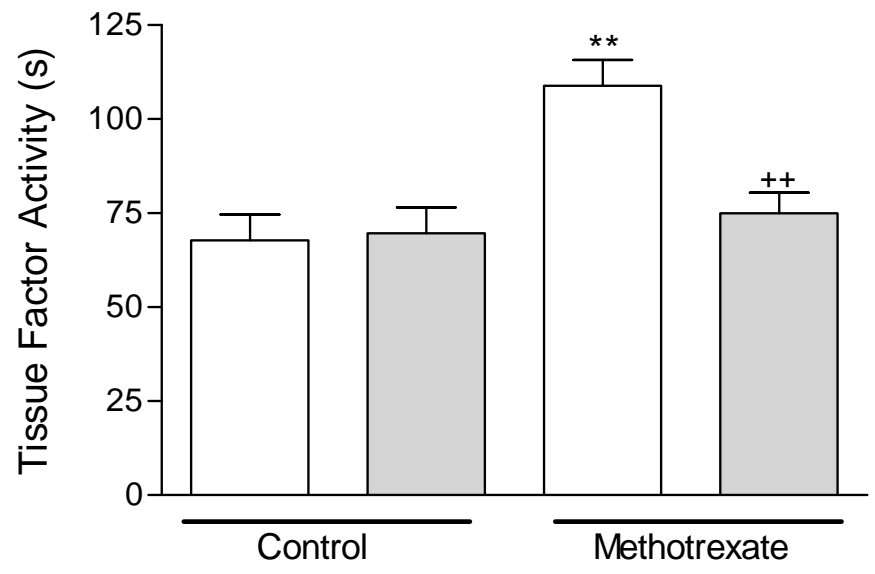

$\square$ saline-treated resveratrol-treated

Figure 3: TF activity of liver tissue in saline- or resveratrol treated control and MTX groups. Each group consists of eight animals. $+++\mathrm{p}<0.01$ compared with methotrexate (MTX) group. 


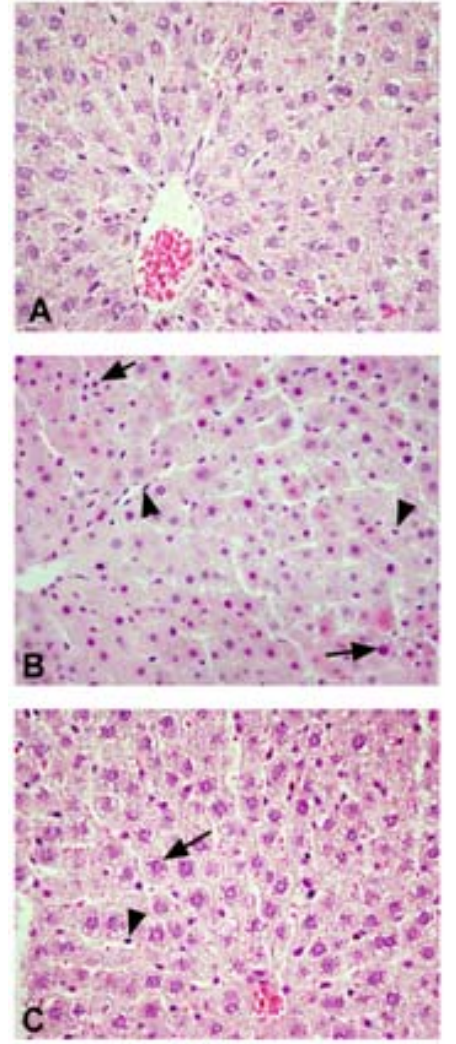

Figure 4. Photomicrographs of liver tissue. Control groups: Normal histological appearance of liver tissue (A); MTX-treated groups: degenerated hepatocytes (arrow) and increased number of activated Kupffer cells (arrow head); MTX + resveratrol-treated groups: regular hepatocytes in most region (arrow), and mild activated Kupffer cells (arrow head) (C). H\&E staining, original magnifications: $\times 200$.

Regarding the mechanisms of methotrexate (MTX) hepatotoxicity, several hypotheses have been put forward, among which oxidative stress (including depletion of glutathione) is likely. The cytosolic $\mathrm{NAD}(\mathrm{P})$-dependent dehydrogenases (30) and NADP malic enzyme are inhibited by MTX, suggesting that the drug could decrease the availability of NADPH in cells (31). Under normal conditions, NADPH is used by glutathione reductase to maintain the reduced state of cell glutathione, which is known as an important cytosolic antioxidant, protective against reactive oxygen species (ROS). Thus, the significant reduction in $(\mathrm{GSH})$ levels promoted by MTX, leads to a reduction of effectiveness of the antioxidant enzyme defense system, sensitizing the cells to ROS (24). Considering the relationship between GSH and the deleterious effects of MTX, interest has been focused on compounds that act as antioxidants and are capable of stimulating GSH synthesis (32).

In the present study elevated serum LDH, AST, ALT activities and tissue collagen levels clearly shows the damaging effect of MTX treatment on the liver.

Resveratrol is both a free radical scavenger and a potent antioxidant because of its ability to promote the activities of a variety of antioxidant enzymes. The ability of the polyphenolic compounds to act as antioxidants depends on the redox properties of their phenolic hydroxyl groups and the potential for electron delocalization across the chemical structure (7, 33).

In our study, resveratrol brought about a reduction in lipid peroxidation products and increased the GSH levels in hepatic tissue, as well as in plasma antioxidant capacity, suggesting the antioxidant and free-radical scavenging activity of resveratrol may reduce the toxic effects of MTX. Cetin et al (34) also have showed that increased level of malondialdehyde and decreased activities of superoxide dismutase and catalase in MTX induced oxidative liver injury has been reversed by grape seed extract administration. Uphadhay et al have showed that resveratrol not only modulates liver toxicity markers but also alters many forms of phase I and phase II xenobiotic metabolizing enzymes both at the level of transcription (mRNA level), as well as at the level of catalytic activity (35). Bujanda et al have also mentioned that resveratrol reduces mortality and liver damage produced by alcohol in mice (36).

In the present study markedly increased hepatic tissue collagen content in MTX-treated group shows the enhanced tissue fibrinolytic activity. Enhanced fibrinolytic activity can create obstructions and produce increased toxic waste products surrounding the hepatic cells within the hepatic tissues. Resveratrol administration to the MTX group significantly decreased the hepatic collagen content. As shown by microscopic evaluation degenerated hepatocytes, increased number of activated Kupffer cells and inflammatory cell infiltration around portal area and central vein. In MTX-treated group clearly shows the hepatic damage caused by MTX. Resveratrol treatment to MTX group improved hepatocytes and decreased the activation of Kupffer cells of the liver.

Both clinical and experimental studies have shown that any noxious event is preceded by tissue macrophages and monocytes, which in turn secrete cytokines such as interleukin-1 (IL-1) and 
TNF- $\alpha$ (37). As evidenced in the present study, MTX administration resulted in increased serum TNF- $\alpha$, indicating the role of this cytokine in this toxicity, while resveratrol depressed the TNF- $\alpha$ response. Moreover, resveratrol treatment decreased the MTX-induced elevation in serum LDH, AST and ALT levels indicating restorative effect of resveratrol on the liver.

It has been shown that free radicals trigger the accumulation of leukocytes in the tissues and activated neutrophils secrete enzymes (e.g., myeloperoxidase, elastase, proteases) and liberate more free radicals. Therefore, MPO plays a fundamental role in oxidant production by neutrophils (38). In our observation, elevated MPO levels in the liver indicate that neutrophil accumulation contributes to MTX-induced oxidative organ injury. MTX-induced elevation in MPO activity was inhibited by resveratrol treatment, indicating that the antioxidative effect of resveratrol may be neutrophil-dependent.

A decrease in TF activity in liver tissue following MTX administration is reversed by resveratrol treatment.TF, also known as thromboplastin or Factor III, is an important coagulation factor that initiates extrinsic blood coagulation with FVII. TF is not a stabile protein. Its activity can easily be changed by the alterations in membrane composition, heating, changing in $\mathrm{pH}$, or the lipid peroxidation of membrane due to oxidative stress. Although TF activity was studied in various animal models, it is still unclear which mechanisms regulate the tissue TF activity during liver damage. It is not actively found in the blood but as a component of the cell membranes $(39,40)$. It has been shown that some body fluids have TF activities $(41,42)$. As TF activity has been measured by prothrombin time test, prolonged clot formation time shows decreased TF activity. In the present study, MTX administration decreased TF activity of the liver tissue; this finding can be correlated to the bleeding tendency. Resveratrol treatment increased the TF activity to the normal levels. This may show the healing of the liver tissue after resveratrol administration in MTX induced toxicity.

In conclusion, this study illustrate that resveratrol is capable of reversing the oxidative toxic effects of MTX in the liver. The present study also encourages new experimental and clinical studies to evaluate the efficacy of resveratrol as an adjunctive agent to ameliorate the toxic side effects of chemotherapeutics that cause oxidative tissue injury. In order, therefore, to determine its overall efficacy for treating neoplastic diseases, sensitive tests of liver may have to be conducted.

Novelty of the Work: This study illustrate for the first time that MTX-induced elevation in MPO activity was inhibited by resveratrol treatment, indicating the antioxidative effect of resveratrol may be neutrophil-dependent. The present study also shows restorative effect of resveratrol in the MTX- induced liver toxicity for the first time by measuring lactate dehydrogenase, AST and ALT activities. However, tissue factor activity of the liver is a novel parameter that is measured in this toxicity and in resveratrol treatment. Another original finding is about increased serum TNF- $\alpha$, indicating the role of this cytokine in this toxicity, while resveratrol depressed the TNF- $\alpha$ response.

\section{REFERENCES}

1. Jolivet J, Cowan KH, Curt GA. Clendeninn NJ, Chabner BA. The pharmacology and clinical use of methotrexate. N Engl J Med, 1983; 309:10941104.

2. Braun J, Rau R. An update on methotrexate. Curr Opin Rheumatol, 2009; 21: 216-223.

3. Guzzo C. Folic acid supplementation with methotrexate therapy: What benefit if any? J Am Acad Dermatol, 1994; 31: 689.

4. Zachariae H. Liver biopsies and methotrexate: a time for reconsideration? J Am Acad Dermatol, 2000; 42:531-534.

5. Henning JS, Gruson LM, Strober BE. Reconsidering liver biopsies during methotrexate therapy, J Am Acad Dermatol, 2007; 56: 893-894.

6. Schmiegelow K. Advances in individual prediction of methotrexate toxicity: a review. $\mathrm{Br} \mathrm{J}$ Haematol, 2009; 146:489-503.

7. Ignatowicz E, Baer-Dubowska W. Resveratrol, a natural chemopreventive agent against degenerative diseases. Pol J Pharmacol, 2001; 53: 557-569.

8. Soleas GJ, Yan J, Goldberg DM Absorption of trans-resveratrol in rats. Methods Enzymol, 2001; 335: 130-145.

9. Leonard S, Xia C, Jiang BH, Stinefelt B, Klandorf H, Harris GK, Shi X. Biochem Biophys Res Commun, 2003; 309: 1017-1026.

10. Gusman J, Malonne H, Atassi G. A reappraisal of the potential chemopreventive and chemo therapeutic properties of resveratrol. Carcinogenesis, 2001; 22: 1111-1117.

11. Jang M Pezzuto JM. : Cancer chemopreventive activity of resveratrol. Drug Exp Clin Res, 1999; 25: 65-77.

12. Mayo JC, Tan DX, Sainz RM, Natarajan M, Lopez-Burillo S, Reiter RJ. Protection against 
oxidative protein damage induced by metalcatalyzed reaction or alkylperoxyl radicals: comparative effects of melatonin and other antioxidants. Biochim Biophys Acta, 2003; 1620: 139-150.

13. Zini R, Morin C, Bertelli A, Bertelli AA, Tillement JP . Drugs Exp Clin Res, 1999; 25: 8797.

14. MartínezJ, Moreno JJ. Effect of resveratrol, a natural polyphenolic compound, on reactive oxygen species and prostaglandin production. Biochem Pharmacol, 2000; 59: 865-870.

15. Losa GA. Resveratrol modulates apoptosis and oxidation in human blood mononuclear cells. Eur J Clin Invest, 2003; 33: 818-823.

16. Orallo F, Alvarez E, Camina M, Leiro JM, Gomez E, Fernandez P. The possible implication of transResveratrol in the cardioprotective effects of longterm moderate wine consumption. Mol Pharmacol, 2002; 61: 294-302.

17. Beuge JA, Aust SD. Microsomal lipid peroxidation. Methods Enzymol, 1978; 52:302311.

18. Beutler, E., Glutathione in red blood cell metabolism, in: A manual of biochemical methods. New York: Grune and Stratton, pp 112114, 1975.

19. Hillegas LM, Griswold DE, Brickson B, Albrightson-Winslow C. Assesment of myeloperoxidase activity in whole rat kidney. $\mathrm{J}$ Pharmacol Methods, 1990; 24:285-295.

20. Ingram GI, Hills M. Reference method for the one-stage prothrombin-time test on human blood. Thromb Haemost, 1976; 36: 237-238.

21. Lopez De Leon A, Rojkind M. A simple micromethod for collagen and total protein determination in formalin-fixed paraffin embedded sections. J Histochem Cytochem, 1985; 33:737-743.

22. Neuman MG, Cameron RG, Haber JA, Katz GG, Malkewcz IM, Shear NH. Inducers of cyto-chrome P450 2E1 enhance methotrexate induced hepatotoxicity. Clin Biochem, 1999; 32:519-536.

23. Krajinovic M, Moghrabi A. Pharmacogenetics of methotrexate. Pharmacogenomics, 2004;5, 819834.

24. Babiak RM, Campello AP, Carnieri EG, Olivera MB. Methotrexate: pentose cycle and oxidative stress. Cell Biochem Funct, 1998; 16: 283-293.

25. Chladek J, Martinkova J, Sispera L. An in vitro study on methotraxate hydoxylation in rat and human liver. Physiol Res, 1997; 46:371-379.

26. Galivan J, Nimec Z, Balinska M. Regulation of methotrexate polyglutamate accumulation in vitro: effects of cellular folat content. Biochem Pharmacol, 1983; 32:3344-3347.

27. Kamen BA, Nylen PA, Camitta BM, Bertno JR. Methotrexate accumulation and folate depletion in cell as a possible mechanism of chronic toxicity to the drug. Br J Hematol, 1981; 49:355-360.
28. Prey S, Paul C. Effect of folic or folinic acid supplementation on methotrexateassociated safety and efficacy in inflammatory disease: a systematic review. Br J Dermatol, 2008; 160:622-628.

29. Kremer JM, Galivan J, Streckfuss A, Kamen B. Methotrexate metabolism analysis in blood and liver of rheumatoid arthritis patients. Arth Rheum, 1986; 29:832-835.

30. Vogel WH, Snyder R, Schulman MP. The inhibition of dehydrogenases by folic acid and several of its analogs. Biochim Biophys Res Comm, 1963; 10:97-101.

31. Caetano NN, Campello AP, Carnieri EGS, Kluppel MLW, Oliveira MBM. Effects of methotrexate (MTX) on NAD(P) ${ }^{+}$dehydrogenases of HeLa cells: malic enzymes, 2-oxoluterate and isocitrate dehydrogenases. Cell Biochem Funct, 1997; 15:259-264.

32. Jahovic N, Cevik HA, Sehirli O, Yegen BC, Sener G. Melatonin prevents methotrexate-induced hepatorenal oxidative injury in rats. J Pineal Res, 2003; 34:282-287

33. Pervaiz S. Resveratrol: from grapevines to mammalian biology. FASEB J, 2003;17: 1975-85.

34. Cetin A, Kaynar L, Kocyigit I, Hacioglu SK, Saraymen R, Ozturk A, Sari I, Sagdic O. Role of grape seed extract on methotrexate induced oxidative stress in rat liver.Am $\mathrm{J}$ Chin Med, 2008;36; 861-872.

35. Upadhyay G, Singh AK, Kumar A, Prakash O, Singh MP. Resveratrol modulates pyrogallolinduced changes in hepatic toxicity markers, xenobiotic metabolizing enzymes and oxidative stress. Eur J Pharmacol, 2008; 596: 146-152.

36. Bujanda L, García-Barcina M, Gutiérrez-de Juan V, Bidaurrazaga J, de Luco MF, Gutiérrez-Stampa M, Larzabal M, Hijona E, Sarasqueta C, Echenique-Elizondo M, Arenas JI. Effect of resveratrol on alcohol-induced mortality and liver lesions in mice. BMC Gastroenterol, 2006; 6:35.

37. Lin HI, Chu SJ, Wang D, Feng NH. Pharmacological modulation of TNF production in macrophages. J Microbiol Immunol Infect, 2004; 37: 8-15.

38. Sullivan GW, Sarembock IJ, Linden J. The role of inflammation in vascular diseases. J Leukoc Biol, 2000; 67:591-602.

39. Bachlie E. History of tissue factor. Br J Haematol, 2000; 110: 248-255.

40. Lwaleed BA, Francis JL, Chrisholm M. Urinary tissue factor levels in neoplastic disease. Ann Saudi Med, 2000; 20: 197-201.

41. Tutuarima JA, Hische EAH, Trotsenburg L, Helm, HJ. Thromboplastic activity of cerebrospinal fluid in neurological disease. Clin Chem, 1985; 31: 99100.

42. Yarat A, Tunali T, Pisiriciler R Akyuz S, Ipbuker A, Emekli N. Salivary thromboplastic activity in diabetics and healthy controls. Clin Oral Invest, 2004; 8: 36-39. 